\title{
Advising vaccinations for the elderly: a cross-sectional survey on differences between general practitioners and physician assistants in Germany
}

Carolina Judith Klett-Tammen ${ }^{1,2}$, Gérard Krause ${ }^{1,3}$, Thomas von Lengerke ${ }^{4}$ and Stefanie Castell ${ }^{1 *}$

\begin{abstract}
Background: In Germany, the coverage of officially recommended vaccinations for the elderly is below a desirable level. It is known that advice provided by General Practitioners and Physician Assistants influences the uptake in patients $\geq 60$ years. Therefore, the predictors of advice-giving behavior by these professions should be investigated to develop recommendations for possible actions for improvement.

Methods: We conducted a postal cross-sectional survey on knowledge, attitudes and advice - giving behavior regarding vaccinations in the elderly among General Practitioners and Physician Assistants in 4995 practices in Germany. To find specific predictors, we performed logistic regressions with non-advising on any officially recommended vaccination or on three specific vaccinations as four separate outcomes, first using all participants, then only General Practitioners and lastly only Physician Assistants as our study population.

Results: Participants consisted of 774 General Practitioners and 563 Physician Assistants, of whom overall $21 \%$ stated to have not advised an officially recommended vaccination in elderly patients. The most frequent explanation was having forgotten about it. The habit of not counselling on vaccinations at regular intervals was associated with not advising any vaccination (OR: 2.8), influenza vaccination (OR: 2.3), and pneumococcal vaccination (OR: 3.1). While more General Practitioners than Physician Assistants felt sufficiently informed ( $90 \%$ vs. $79 \%, p<0.001$ ), General Practitioners displayed higher odds to not advise specific vaccinations (ORs: 1.8-2.8).

Conclusions: To reduce the high risk of forgetting to advice on vaccinations, we recommend improving and promoting standing recall-systems, encouraging General Practitioners and Physician Assistants to counsel routinely at regular intervals regarding vaccinations, and providing Physician Assistants with better, tailor-made information on official recommendations and their changes.
\end{abstract}

Keywords: Vaccination, Elderly, Aged, General practitioners, Physician assistants, Health knowledge, Attitudes, Practice

\footnotetext{
* Correspondence: Stefanie.Castell@helmholtz-hzi.de

${ }^{1}$ Department for Epidemiology, Helmholtz Centre for Infection Research,

Inhoffenstr. 7, Braunschweig 38124, Germany

Full list of author information is available at the end of the article
} 


\section{Background}

Recommendations of the German Standing Committee on Vaccination (STIKO) include influenza vaccination (IV), tetanus vaccination (TV) and pneumococcal vaccination (PV) for individuals who are 60 years or older [1]. These officially recommended vaccinations are financially compensated by the statutory health insurances [2] as the benefit risk ratio of the recommended vaccines has been assessed to be positive [3, 4]. Although general practitioners (GP) are mostly self-employed and therefore have to care for the economic aspects of their practice, they receive an appointed amount for a specific service. As there are several associations of statutory health insurance physicians for different regions in Germany and each negotiates the compensation for the physicians for specific services with the statutory health insurances, the specific compensation for vaccinations might differ.

Vaccination coverage for PV in the elderly is as low as $31 \%$ in Germany [5]; for IV, it is with $37 \%$ clearly lower than the target of $75 \%$ vaccination in the elderly [6], given by the World Health Organization [7]; while it is high for TV with 93 - $95 \%$ [5]. Mostly, GP and physician assistants (PA) advice on vaccinations, and recommendations by these professions influence the vaccination uptake especially in the elderly [8-10]. In Germany, PA assist physicians regarding checkups, treatment, care and counselling of patients and organizational and administrational aspects, but do not treat or counsel autonomously. It can be assumed that in almost every non-private general practice in Germany, at least one PA works. PA themselves cannot open a practice and treat patients but only assist physicians [11]. However, while there is some basic evidence from the year 2000/2001 regarding knowledge, attitude, and practice (KAP) factors with respect to vaccinations in the elderly in German GP [12] and predictors for advising specific vaccines to individuals in this agegroup in American [13] and Australian [14] physicians, PA have been neglected in vaccination-related research in Germany so far. To our knowledge, there has been no study analyzing vaccination-related KAP or KAP as predictors for advice-giving behavior towards the elderly in GP and PA for TV, IV and PV in a sample representative for Germany using multivariable analyses. Therefore, we conducted a survey in both professions in Germany and explored - within the KAP-framework - predictors for not giving vaccination advice to the elderly in general, and on TV, IV, and PV specifically, to gain insight into opportunities for profession specific improvement of advice-giving behavior.

\section{Methods}

We developed two KAP-questionnaires (for GP and PA specifically), and piloted them, using cognitive pretestinterviews as think-aloud, comprehension, category selection and information retrieval probing and confidence rating [15] in 16 persons. We assembled a database comprising all German GP treating adult patients with statutory health insurance using publicly accessible data from the federal associations of statutory health insurance physicians and the medical councils; and then selected a random sample of 5000 practices, stratified and weighted for federal state. We mailed two questionnaires to each selected practice in March 2015. All questionnaire variables and their definitions are presented in Additional file 1.

We evaluated the representativeness of our study population by chi-square tests, using the atlas of physicians [16] for age-distribution and location of practice, i.e. working in East/West Germany with Berlin as East of GP, the statistics of physicians [17] for sex-distribution of the physicians, and the statistics of employees in health service [18] for sex- and age-distribution of PA as data on the source populations.

We performed logistic regressions for each of the four outcomes, i.e., reporting not having recommended any vaccination/TV/IV/PV despite official STIKOrecommendation and in the absence of contraindication in the elderly. Each regression was modelled three times: including all participants, only GP, and only PA, excluding PA that did report to be not responsible for vaccination counseling in their practice $(n=107)$. We included all variables with $p<0.25$ in bivariate analyses (using $\mathrm{chi}^{2}$-test for nominal variables, $t$-test for normally distributed metric, and Mann-Whitney-U for not normally distributed metric and ordinal variables, with the distribution tested graphically and by ShapiroWilk-test) and applied backward selection with $p<0.2$ as model inclusion criteria. If more than $5 \%$ of missing values in predictor variables occurred, we used chainmultiple imputations with five datasets for multivariable analyses. Otherwise and in bivariate analyses, we conducted complete case analyses. For multivariable analysis, we used the GP answer for the PA when GP and PA from the same practice stated to work in different parts of Germany $(n=272)$. We report associations with $p<0.05$ as statistically significant. All analyses were carried out using Stata 12.

\section{Results}

\section{Study population}

Of the netto-sample of 4995 practices, $16.3 \%$ returned questionnaires $(813 / 4995)$ corresponding to $13.4 \%$ eligible participants (1337/9990) (Fig. 1).

Median age of GP was 54 years (interquartile range (IQR): 48-61), median time working as GP was 17 years (IQR: $10-24), 47 \%$ of the respondents were female and $77 \%$ worked in the Western part of Germany. Median age of PA was 43 years (IQR: 30-51), median time 


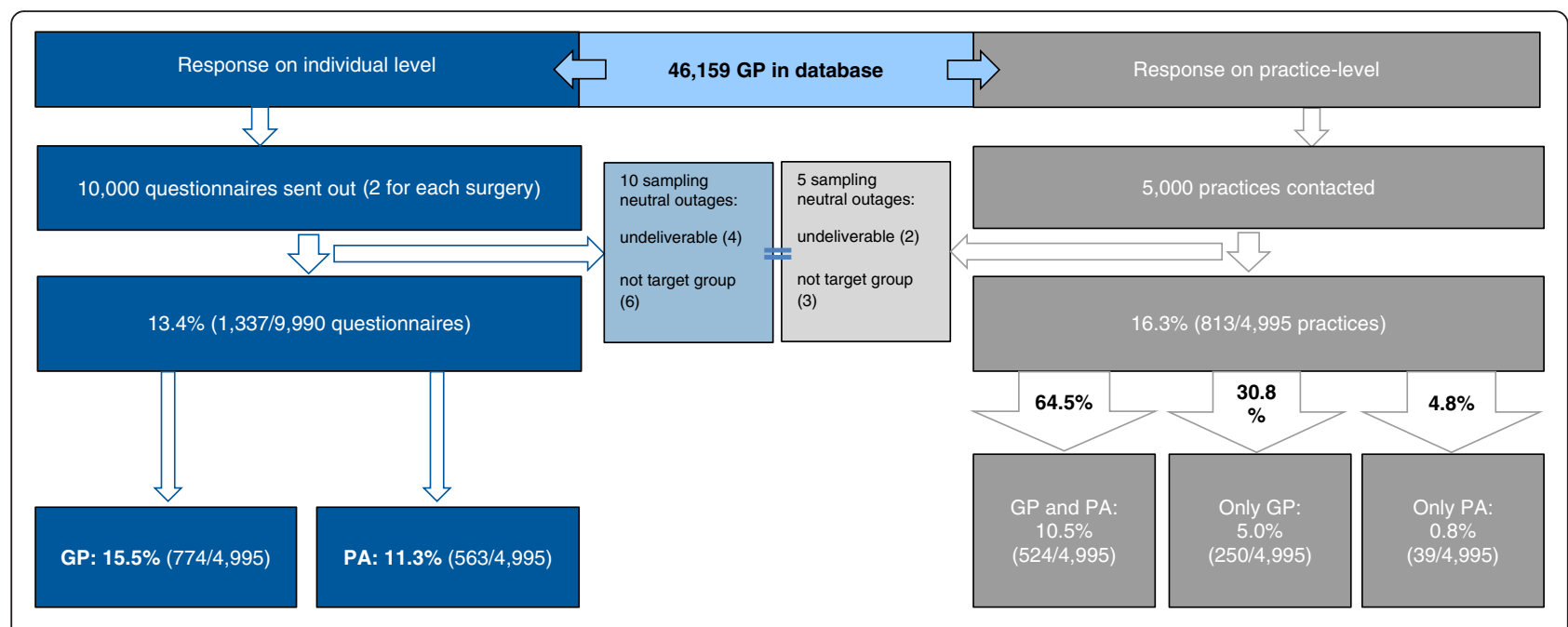

Fig. 1 Description of response on individual and practice-level

working with a GP was 20 years (IQR: 10-30), and $97 \%$ of the respondents were female.

Regarding age-distribution, we found no significant difference between our study population and the source population for both professions (all $p>0.05$ ); regarding location of practice, we found no difference for GP $(p>0.05)$, while more female GP (47 \% vs $43 \%, p=0.02)$ and more male PA ( $3 \%$ vs. $2 \%, p=$ 0.03) participated.

\section{Description of knowledge, attitude, and practices}

Of all participants, 265 (22\%) stated to have not advised at least one vaccination to an elderly patient despite STIKO-recommendation and absence of a contraindication. PV was the vaccination most frequently not being suggested $(n=183)$, i.e. $15 \%$ of all participants involved in counseling on vaccinations, or $19 \%(148 / 774)$ of GP respectively. Most participants reported to know (92\%, $1235 / 1337)$ and to trust $(90 \%, 1200 / 1337)$ the STIKOrecommendations. Whereas $85 \%(1140 / 1337)$ of the respondents felt in general sufficiently informed about vaccinations in the elderly, $66 \%(880 / 1337)$ required better information on changes of STIKO-recommendations. Respondents supported (95 \%, 1265/1337) discussions about vaccinations being initiated by patients and utilized this as an opportunity to counsel (92\%, 1232/ 1337) (Table 1).

The most common explanations given by respondents for not advising was for all three investigated vaccinations forgetting to advise (53-72\%), followed by the perceived low risk of the patient to catch the respective disease (23-28\%). Uniquely for IV, 19 participants $(14 \%)$ stated to not have advised it due to safety concerns and 21 (15\%) due to doubts on its effectiveness (Table 2).

\section{Predictors for not advising vaccinations}

In multivariable analyses, odds ratios $(\mathrm{OR})>1$ imply that the influencing factor increases the chance of not having advised a vaccination to elderly, while $O R<1$ signify an increasing chance that a vaccination is always advised when medically indicated and recommended by STIKO.

Most prominent predictor for any $(4.4,1.0-19.4)$ and tetanus vaccination $(4.9,1.5-16.5)$ is not trusting the STIKO-recommendations; although this concerns only $2 \%$ of respondents (25/1337). For influenza $(7.8,3.6-$ $16.9)$ and pneumococcal vaccination $(3.5,1.5-8.2)$, the negative perceived benefit-harm-ratio of the respective vaccine showed the most substantial association for not advising it to the elderly. While working in WestGermany more than doubles the odds for not advising any vaccination $(2.9,1.7-4.9)$, IV $(2.4,1.3-4.5)$ and PV $(2.8,1.6-5.1)$, this association is not significant in the model for TV. Not counseling on vaccinations at regular intervals, e.g. at the first visit of a patient within an accounting period, is associated with not advising any vaccination (2.8, 1.5-5.3), IV (2.3, 1.1-5.1), and PV (3.1, 1.5-6.7). GP exhibit about two times the odds for not having advised specific vaccinations compared to PA (TV: 2.8, 1.5-5.4; IV: 2.6, 1.5-4.6; PV: 1.8, 1.1-3.0) (Fig. 2, Additional file 2).

\section{Comparison of general practitioners and physician assistants}

PA supported GP regarding counseling on vaccinations in $79 \%(612 / 813)$ of responding practices. Despite the higher chance of GP to not have advised all investigated vaccinations in the elderly compared to PA, more GP than PA felt sufficiently informed regarding vaccinations in adults (90\% of GP (696/774) vs. $79 \%$ of PA (444/563), $p<0.001)$, stated to know STIKOrecommendations (97\% of GP $(752 / 774)$ vs. $86 \%$ of 
Table 1 Knowledge, attitude, practice regarding vaccinations in the elderly in general practitioners (GP) and physician assistants (PA)

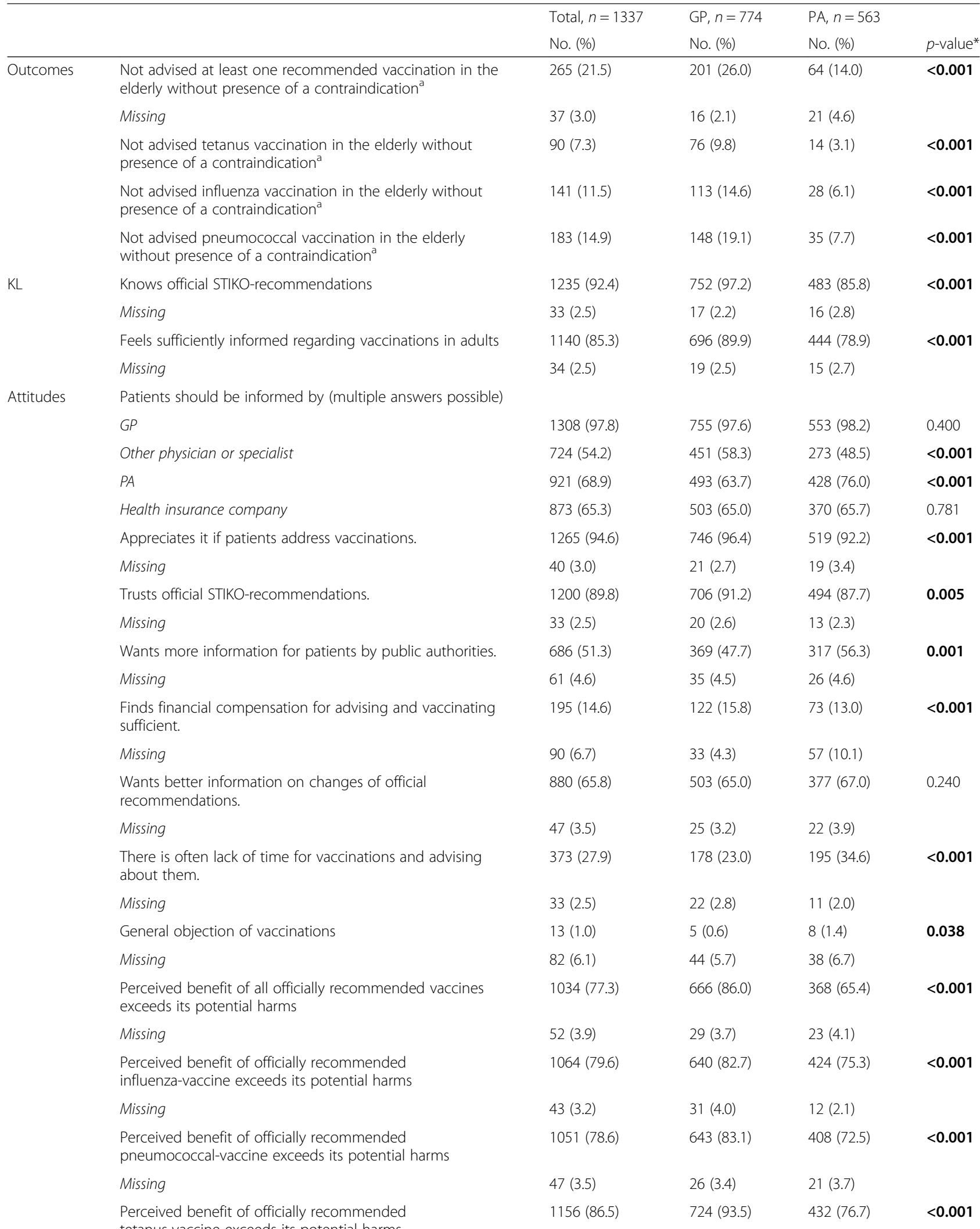


Table 1 Knowledge, attitude, practice regarding vaccinations in the elderly in general practitioners (GP) and physician assistants (PA) (Continued)

\begin{tabular}{|c|c|c|c|c|c|}
\hline & Missing & $19(1.4)$ & 0 & $19(3.4)$ & \\
\hline & $\begin{array}{l}\text { Cause that vaccination recommendations are not well } \\
\text { implemented }\end{array}$ & & & & $<0.001$ \\
\hline & Physicians & $74(5.5)$ & $51(6.6)$ & $23(4.1)$ & \\
\hline & Patients & $376(28.1)$ & $162(20.9)$ & $214(38.0)$ & \\
\hline & Both & $757(56.6)$ & $510(65.9)$ & $247(43.9)$ & \\
\hline & None of them & $89(6.7)$ & $31(4.0)$ & $58(10.3)$ & \\
\hline & Missing & $41(3.1)$ & $20(2.6)$ & $21(3.7)$ & \\
\hline & Likes to counsel about vaccinations $^{a}$ & $1078(87.6)$ & $683(88.2)$ & $395(86.6)$ & 0.299 \\
\hline & Missing & $27(2.2)$ & $17(2.2)$ & $10(2.2)$ & \\
\hline \multirow[t]{15}{*}{ Practices } & $\begin{array}{l}\text { Opportunities for vaccinations counselling (multiple } \\
\text { answers possible) }\end{array}$ & & & & \\
\hline & Patient addresses it & $1232(92.1)$ & $710(91.7)$ & $522(92.7)$ & 0.508 \\
\hline & Travel plans & 1225 (91.6) & 701 (90.6) & $524(93.1)$ & 0.103 \\
\hline & Preventive checkup & $1205(90.1)$ & $715(92.4)$ & $490(87.0)$ & 0.001 \\
\hline & Injuries & 1198 (89.6) & $687(88.8)$ & $511(90.8)$ & 0.236 \\
\hline & First contact with patient & $716(53.16)$ & $442(57.1)$ & $274(48.7)$ & 0.002 \\
\hline & Indication of a recall-system & $312(23.3)$ & $170(22.0)$ & $142(25.2)$ & 0.164 \\
\hline & Routinely at regular intervals & $225(16.8)$ & $124(16.0)$ & $101(17.9)$ & 0.354 \\
\hline & $\begin{array}{l}\text { Source of information regarding vaccines (multiple } \\
\text { answers possible) }\end{array}$ & & & & \\
\hline & Continuous (online) training & $756(56.5)$ & $464(59.9)$ & $292(51.9)$ & 0.003 \\
\hline & Professional journals & $812(60.7)$ & $578(74.7)$ & $234(41.6)$ & $<0.001$ \\
\hline & Conferences & $354(26.5)$ & $305(39.4)$ & $49(8.7)$ & $<0.001$ \\
\hline & Pharmaceutical representative & $692(51.8)$ & $359(46.4)$ & $333(59.1)$ & $<0.001$ \\
\hline & Professional association & $147(11.0)$ & $107(13.8)$ & $40(7.1)$ & $<0.001$ \\
\hline & STIKO & $1050(78.5)$ & $662(85.5)$ & $388(68.9)$ & $<0.001$ \\
\hline
\end{tabular}

GP General Practitioner, PA Physician Assistant, KL Knowledge

${ }^{*} p$-values $<0.05$ in bold letters ( $\mathrm{Chi}^{2}$-Test for differences between GP and PA without missings)

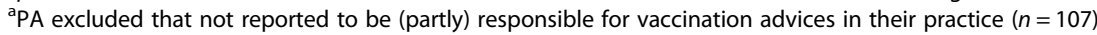

PA (483/563), $p<0.001)$, and to use them as a source of information (85\% of GP $(662 / 774)$ vs. $69 \%$ of PA (388/563), $p<0.001)$. For all investigated vaccinations, less PA than GP believed the benefit to exceed potential harms (all $p<0.001)$ (Table 1).

Modelling GP and PA separately indicates that e.g. location of the practice in the Western part of Germany, and not counseling routinely at regular intervals increases the chance for not advising on any vaccination only in GP, whereas e.g. age-structure of practices' patients is only a significant predictor in PA (Table 3, Additional file 3).

\section{Discussion}

Over $20 \%$ of the participants stated that they had not advised at least one officially recommended vaccination, even in absence of any specific contraindication; with $26 \%$ of the GP and $14 \%$ of the PA, significantly more physicians than assistants reported a vaccination-advise practice deviating from recommendations. By far the most frequent explanation in both professions was "having forgotten to advise". More than $20 \%$ of PA did not feel sufficiently informed regarding vaccinations in adults (vs. $10 \%$ of the GP); $90 \%$ of the respondents stated that they trusted the official STIKOrecommendations, and very few were general opponents of vaccination. Only $17 \%$ of the participants counsel routinely at regular intervals and just $23 \%$ use a recall-system. In general, the chance of not advising is higher in practices in West-Germany and with younger patients. Also, those who do not counsel routinely at regular intervals, those with a neutral attitude towards counseling, and who do not trust the STIKOrecommendations have a higher chance of not advising. Overall, associations with KAP-variables were rather similar across different vaccines, while we observed 
Table 2 Reasons for not advising specific vaccinations despite STIKO-recommendation and in the absence of any contraindication (multiple answers possible)

\begin{tabular}{|c|c|c|c|c|c|c|c|c|c|}
\hline & \multicolumn{3}{|c|}{ Total $^{a}(n=1230)$} & \multicolumn{3}{|c|}{ General practitioners $(n=774)$} & \multicolumn{3}{|c|}{ Physician assistants $^{\mathrm{a}}(n=456)$} \\
\hline & $\begin{array}{l}\text { Tetanus } \\
(n=90)\end{array}$ & $\begin{array}{l}\text { Influenza } \\
(n=141)\end{array}$ & $\begin{array}{l}\text { Pneumococcal } \\
(n=183)\end{array}$ & $\begin{array}{l}\text { Tetanus } \\
(i=76)\end{array}$ & $\begin{array}{l}\text { Influenza } \\
(n=113)\end{array}$ & $\begin{array}{l}\text { Pneumococcal } \\
(n=148)\end{array}$ & $\begin{array}{l}\text { Tetanus } \\
(n=14)\end{array}$ & $\begin{array}{l}\text { Influenza } \\
(n=28)\end{array}$ & $\begin{array}{l}\text { Pneumococcal } \\
(n=35)\end{array}$ \\
\hline & No. (\%) & No. (\%) & No. (\%) & No. (\%) & No (\%) & No (\%) & No. (\%) & No (\%) & No. (\%) \\
\hline Disease is harmless & 0 & $4(2.8)$ & $3(1.6)$ & 0 & $2(1.8)$ & $2(1.4)$ & 0 & $2(7.1)$ & $1(2.9)$ \\
\hline Forgot to advise & $65(72.2)$ & $74(52.5)$ & $129(70.5)$ & $56(73.7)$ & $60(53.1)$ & $107(72.3)$ & $9(64.3)$ & $14(50.0)$ & $22(62.9)$ \\
\hline Vaccine is ineffective & $2(2.2)$ & $21(14.9)$ & $9(4.9)$ & $2(2.6)$ & $19(16.8)$ & $9(6.1)$ & 0 & $2(7.1)$ & 0 \\
\hline $\begin{array}{l}\text { Does not feel responsible } \\
\text { for vaccinations }\end{array}$ & $7(7.8)$ & $3(2.1)$ & $4(2.2)$ & $5(6.6)$ & 0 & 0 & $2(14.3)$ & $3(10.7)$ & $4(11.4)$ \\
\hline Vaccine is not safe & $1(1.1)$ & $19(13.5)$ & $12(6.6)$ & $1(1.3)$ & $13(11.5)$ & $10(6.8)$ & 0 & $6(21.4)$ & $2(5.7)$ \\
\hline $\begin{array}{l}\text { Was not aware of } \\
\text { recommendation }\end{array}$ & $5(5.6)$ & $2(1.4)$ & $4(2.2)$ & $5(6.6)$ & $2(1.8)$ & $2(1.4)$ & 0 & 0 & $2(5.7)$ \\
\hline $\begin{array}{l}\text { Risk of the patient to } \\
\text { catch disease is low }\end{array}$ & $21(23.3)$ & $38(27.0)$ & $51(27.9)$ & $18(23.7)$ & $33(29.2)$ & $43(29.1)$ & $3(21.4)$ & $5(17.9)$ & $8(22.9)$ \\
\hline $\begin{array}{l}\text { Accounting is too } \\
\text { complicated }\end{array}$ & $3(3.3)$ & $3(2.1)$ & $3(1.6)$ & $1(1.3)$ & $1(0.9)$ & $1(0.7)$ & $2(14.3)$ & $2(7.1)$ & $2(5.7)$ \\
\hline $\begin{array}{l}\text { Reimbursement does not } \\
\text { compensate the effort }\end{array}$ & $8(8.9)$ & $11(7.8)$ & $9(4.9)$ & $4(5.3)$ & $7(6.2)$ & $4(2.7)$ & $4(28.6)$ & $4(14.3)$ & $5(14.3)$ \\
\hline
\end{tabular}

${ }^{a}$ Only Physician Assistants included that stated to be (partly) responsible for vaccination advises in their practice

some significant distinctions between GP and PA. The high proportion of GP and PA working in the Western part of Germany can be explained by the general high proportion of the German population living there $(\sim 16$ million in the Eastern part versus $\sim 65$ million people in the Western part [19]).

There are only few vaccination-related KAP-surveys among GP that address vaccinations in the elderly. A German study, published 16 years ago, found the same geographic difference in following the official recommendations as we did, with GP in the Western part of Germany vaccinating/advising less often than in the east [12]. This matches the observation of general higher vaccination coverage in the Eastern part of Germany [5]. To the $18 \%$ of their respondents never vaccinating against pneumococci, the $19 \%$ of GP in our study, who reported that they had not advised PV (mostly due to having forgotten to do so), seem to be comparable, although the outcomes are not exactly the same, as we did not ask about the actual vaccination, but about advising vaccinations. Opportunities for vaccination were similar to our study, e.g. a majority of $84 \%$ stated to counsel during preventive check-ups and $71 \%$ at first contact with a patient, although, with only $4 \%$, even less participants stated to counsel routinely at regular intervals [12]. The association of the perceived benefit-harm-ratio of the corresponding vaccine with not advising IV and PV which we saw in our results was matched by the result of a survey in the USA [13], where mainly belief-related predictors as perceived vaccine-effectiveness for advising IV and PV were found. In Australia, most common explanations for not giving vaccinations to the elderly by GPs were refusal of patients ( $88 \%)$ and competing priorities (35\%) [14]. In a Canadian study, addressing mainly childhood vaccinations, nurses were also included, showing a more positive attitude towards administering different vaccinations during a single visit than physicians [20], which is in line with the result in our study that less PA than physicians reported advicefailures. As the PA in our study did not show a substantially more positive attitude towards vaccinations, the lower proportion of reported non-advising than in GP could demonstrate a more rule-governed behavior of the PA, a higher vulnerability to a social desirability bias or less knowledge of norms and therefore less conscious deviation of these norms.

So far, PA have been neglected in public health vaccinology in Germany; however, as they also counsel and administer vaccinations $[21,22]$, it would be beneficial to include them in future activities or interventions regarding vaccine-uptake. Our study has generated new knowledge concerning the needs for information of PA and points out attitudes that can be useful to optimize future interventions. Since our study included physicians and their assistants, using mostly the same questions, we were able to compare both professions systematically with respect to knowledge, attitudes and practices. Thus, we found statistically significant differences not only in advice-giving behavior, but also in subjective knowledge of official recommendations and the trust they are met with. This also applies to other aspects like the perceived benefit-harm-ratio of certain vaccines, and practices like the sources of information regarding vaccinations. 


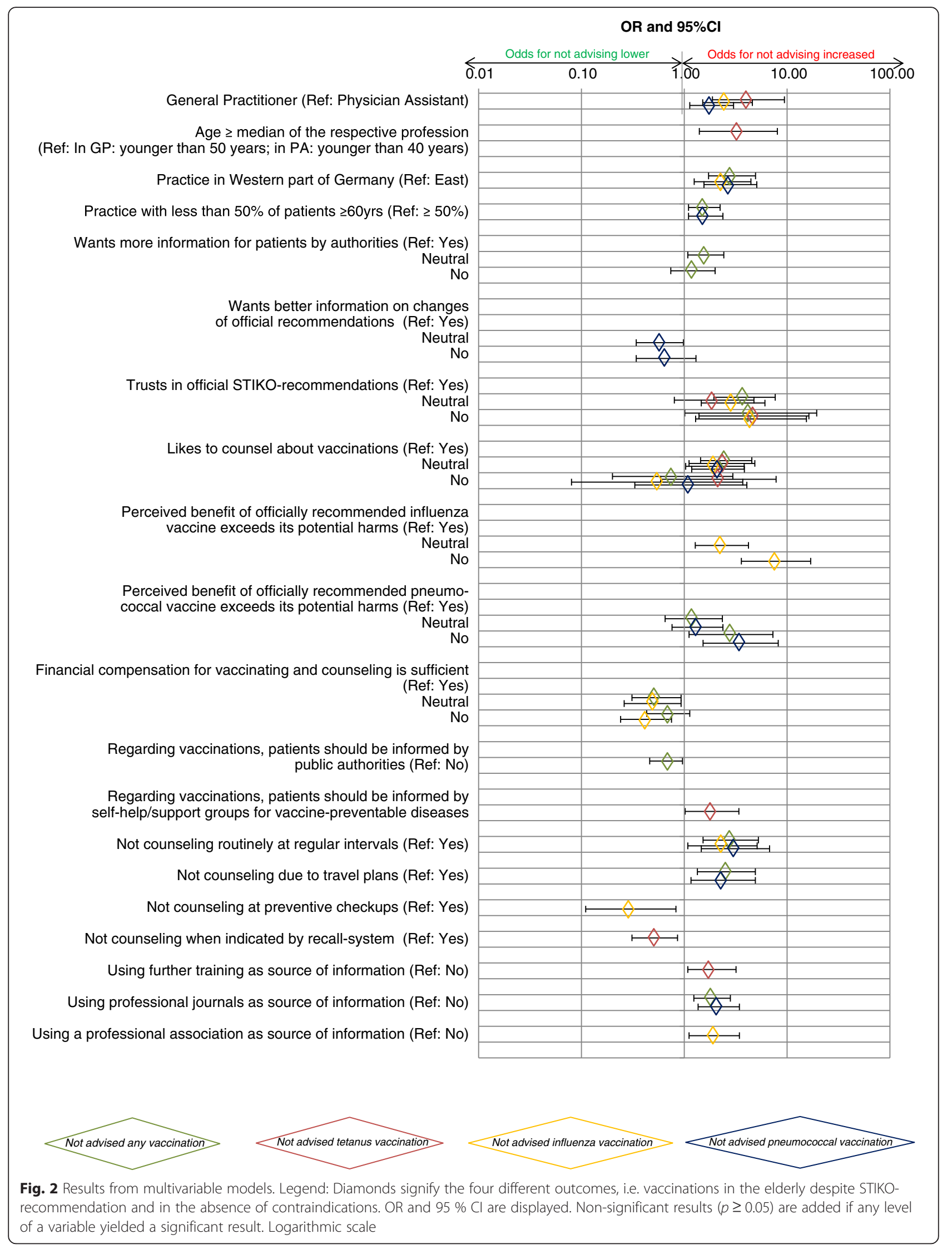


Table 3 Multivariable models for each, GP and PA

\begin{tabular}{|c|c|c|c|c|c|}
\hline & \multirow[b]{2}{*}{ Variables } & \multicolumn{2}{|l|}{$\mathrm{GP}(n=774)$} & \multicolumn{2}{|c|}{$\begin{array}{l}\text { PA that are responsible for vaccination } \\
\text { advices in their surgery }(n=456)\end{array}$} \\
\hline & & OR $(95 \% \mathrm{Cl})$ & $p$-value & OR $(95 \% \mathrm{Cl})$ & $p$-value \\
\hline \multirow[t]{2}{*}{$\overline{\mathrm{SD}}$} & Practice in Western part of Germany (Ref: East) & $2.81(1.59-4.97)$ & $<0.001$ & n.s. & \\
\hline & Amount of patients of $\geq 60$ year less than $50 \%$ (Ref: $\geq 50 \%$ ) & n.s. & & $2.19(1.20-4.00)$ & 0.011 \\
\hline \multirow[t]{15}{*}{ Attitudes } & Trusts in official recommendations & & & n.s. & \\
\hline & Ref: Yes & 1 (Ref) & & & \\
\hline & Neutral & $3.61(1.56-8.32)$ & 0.003 & & \\
\hline & No & $19.30(2.28-163.24)$ & 0.007 & & \\
\hline & Likes to counsel about vaccinations & & & n.s. & \\
\hline & Ref: Yes & 1 (Ref) & & & \\
\hline & Neutral & $2.94(1.56-5.54)$ & 0.001 & & \\
\hline & No & $1.02(0.24-4.27)$ & 0.976 & & \\
\hline & $\begin{array}{l}\text { Benefit of officially recommended pneumococcal vaccine } \\
\text { exceeds its potential harms }\end{array}$ & & & n.s. & \\
\hline & Ref: Yes & 1 (Ref) & & & \\
\hline & Neutral & $1.85(0.99-3.44)$ & 0.054 & & \\
\hline & No & $3.26(1.30-8.14)$ & 0.012 & & \\
\hline & Regarding vaccinations, patients should be informed by: & & & & \\
\hline & General Practitioner (Ref: No) & $0.31(0.10-0.94)$ & 0.038 & n.s. & \\
\hline & Public authorities (Ref: No) & n.s. & . & $0.43(0.21-0.90)$ & 0.026 \\
\hline P & Not counseling routinely at regular intervals (Ref: Yes) & $2.86(1.37-5.96)$ & & & \\
\hline
\end{tabular}

Statistically significant (defined as $p<0.05$ ) associations with not advising at least one vaccination in the elderly despite STIKO-recommendations and no contraindication modelled separately for General Practitioner (GP) and Physician Assistant (PA); non-significant results ( $p \geq 0.05)$ are added if any level of a variable yielded a significant result and are shown in italics

Ref Reference, SD Socio-demographic and practice-characteristics, $P$ Practice, n.s. not significant

\section{Strengths and limitations}

The evaluation of the representativeness regarding age, sex and location of practice by chi-square tests did not indicate any bias in recruitment or response within the German population of GP and PA, despite the low response with $11.3 \%$ in PA and $15.5 \%$ in GP. Still, the variables available for investigating representativeness do not necessarily represent characteristics relevant for the research question at hand. Furthermore, using other statistical test methods might result in different findings. The generalizability of our results is therefore limited.

Due to known difficulties in recruiting GPs for such studies in Germany [23], we chose not to test the knowledge regarding vaccinations, in order not to embarrass and thus repel possible participants. However, we assume our design, i.e. asking how well subjects feel informed, to describe this factor sufficiently well. As we merely assessed self-reported advice-giving behavior, not actually observing the routine, unintentional misperceptions by the participants regarding recommendations, contraindications, or their own behavior, biased responses might be possible. To avoid bias due to lack of awareness of the recommendations for TV, IV and PV, we specifically asked if a vaccination had ever not been recommended to a person of at least 60 years, despite the absence of a contraindication. We also provided the option to state that the participant did not know about above-mentioned recommendations. Still, due to social desirability or recall problems an underestimation of not advising vaccinations by GP and PA is possible.

\section{Conclusions}

By far the most frequent explanation given for not advising a vaccination was forgetting about it, matching the substantial association of not advising any, influenza and pneumococcal vaccination with not counseling routinely at regular intervals. Still, despite improvements in this field (compared to 2000 [12]), only a minority of participants stated that they counselled regularly or used a recall-system. As it is known that many opportunities for counseling on vaccinations are not used [24], an easy-to-implement automated recall-feature complying with legal requirements and integrated in the practice management system seems to be an absolute necessity of modern health care administration. Furthermore, it has to be promoted that these functions exist and how and under which circumstances they can be used for reminding patients and alerting GP and PA $[25,26]$ and 
if there are new developments as automated management of appointments including possibilities for recalls [27]. In most practices, PA also counsel on vaccination, but seem to feel insufficiently informed about vaccinations in adults or changes in STIKO recommendations. Therefore the provision of better edited information (e.g. on efficacy and safety), tailored specifically to the needs of PA might improve the situation significantly. Another option to improve the vaccination rates in the elderly could be to allow for other health care specialists to apply specific vaccinations, as public health services. In Ireland, pharmacists are involved [28] with good results for influenza vaccination $[29,30]$. However, in some areas physicians seem to be the most important source of vaccinations and vaccination counselling [31].

Empowering PA, installing and promoting mechanisms to reduce the risk of forgetting to give vaccination advice and include special vaccination hours in public health services in the vaccinations procedure may open up new avenues to improved vaccination coverage in the elderly.

\section{Additional files}

Additional file 1: Variables: definitions and origins. Description: List of all variables, their definitions and origins. (PDF 239 kb)

Additional file 2: Multivariable analyses of associations with not advising vaccinations despite STIKO-recommendation. Description: Full models including non-significant associations with not advising specific vaccinations. $N=1337$. (PDF $466 \mathrm{~kb}$ )

Additional file 3: Multivariable analyses of associations with not advising vaccinations despite STIKO-recommendation in GPs and PAs separately. Description: Full models including non-significant associations with not advising specific vaccinations. (PDF $446 \mathrm{~kb}$ )

\section{Abbreviations}

GP, general practitioner; IV, influenza vaccination; P, practice; PA, physician assistant; PV, pneumococcal vaccination; SD, socio-demographic and practice-characteristics; STIKO, German standing committee on vaccination; TV, tetanus vaccination.

\section{Acknowledgements}

Denise Muschik, André Karch, and Nicole Rübsamen provided statistical support. Helga Brink provided proof-reading.

The authors thank the General Practitioners and Physician Assistants that participated in the pilot study and in the survey and the experts that gave advice on the questionnaire.

\section{Funding}

The study was partly funded by the Ministry of Science and Culture of Lower Saxony as part of the doctoral program GESA: Health related care for a selfdetermined life in old age - Theoretical concepts, users' needs and responsiveness of the health care system.

\section{Availability of data and materials}

The dataset supporting the conclusions of this article is available upon request at the corresponding author.

\section{Authors' contributions}

SC, GK and CJKT conceived the study; CJKT developed the questionnaire, conducted the survey, and performed the statistical analyses. SC coordinated the survey and the analyses and provided comments and consultation on all aspects of the work. GK provided technical expertise and advice on conducting the survey and on the interpretation of the data. TVL gave advice on all stages of the project. CJKT composed the initial manuscript with contributions from SC; GK and TVL commented. All authors are equally responsible for the content of the manuscript and have read and approved the final manuscript.

\section{Competing interests}

All authors declare no competing interests.

\section{Consent to publish}

Not applicable.

\section{Ethics approval and consent to participate}

All procedures performed in this study involving human participants were in accordance with the institutional and national research committee and with the 1964 Helsinki declaration and its later amendments or comparable ethical standards. The dataset did not include individual personal data. The study was approved by the Ethics committee of Hannover Medical School (No. 2514-2014)

\section{Author details}

1Department for Epidemiology, Helmholtz Centre for Infection Research, Inhoffenstr. 7, Braunschweig 38124, Germany. ${ }^{2}$ Institute for Epidemiology, Social Medicine and Health Systems Research, Hannover Medical School, Hannover, Germany. ${ }^{3}$ Chair for Infectious Disease Epidemiology, Hannover Medical School, Hannover, Germany. ${ }^{4}$ Medical Psychology Unit, Hannover Medical School, Carl-Neuberg-Str. 1, Hannover 30625, Germany.

Received: 24 March 2016 Accepted: 21 July 2016

Published online: 29 July 2016

\section{References}

1. Robert Koch Institute. Announcement of the Standing Committee on Vaccination at Robert Koch Institute (RKI). Recommendations of the Standing Committee on Vaccination (STIKO) at Robert Koch-Institute/ Effective August 2015. Epidemiol Bull. 2015:34(10):327-360.

2. Joint Federal Committee. Guideline regarding vaccinations [SI-RL]. 2015. [https://www.g-ba.de/downloads/62-492-1118/SI-RL_2015-11-27_iK-2016-0206.pdf]. (Retrieved 25.07.2016).

3. Reiter S, Rasch G. Federal Health Monitoring System: Vaccinations. In: Federal Health Monitoring System. vol. 1. Berlin: Robert Koch Institute and Federal Office of Statistics; 2004.

4. Methodology of STIKO for the development of vaccination recommendation. [http://www.rki.de/EN/Content/infections/Vaccination/ methodology/methoden_node.html]. (Retrieved: 25.07.2016).

5. Poethko-Muller C, Schmitz R. Vaccination coverage in German adults: results of the German Health Interview and Examination Survey for Adults (DEGS1). Bundesgesundheitsblatt Gesundheitsforschung Gesundheitsschutz. 2013; 56(5-6):845-57.

6. Robert Koch Institute. Coverage of measles-, HPV-, and influenza vaccination in Germany. Epidemiol Bull. 2016:1:1-7.

7. World Health Organization. Evaluation of seasonal influenza vaccination policies and coverage in the WHO European Region. Results from the 2008/ 2009 and 2009/2010 influenza seasons. Based on a joint VENICE-ECDCWHO survey. Kopenhagen: WHO Europe; 2014.

8. Kyaw M, Nguyen-Van-Tam J, Pearson J. Family doctor advice is the main determinant of pneumococcal vaccine uptake. J Epidemiol Community Health. 1999:53:589-90.

9. Schneeberg A, Bettinger JA, McNeil S, Ward BJ, Dionne M, Cooper C, Coleman B, Loeb M, Rubinstein E, McElhaney J, et al. Knowledge, attitudes, beliefs and behaviours of older adults about pneumococcal immunization, a Public Health Agency of Canada/Canadian Institutes of Health Research Influenza Research Network (PCIRN) investigation. BMC Public Health. 2014;14:442.

10. Johnson D, Nichol K, Lipczynski K. Barriers to adult immunization. Am J Med. 2008;121(7 Suppl 2):S28-35.

11. Description of "Medizinische Fachangestellte". [https://berufenet. arbeitsagentur.de/berufenet/faces/index?path=null/ kurzbeschreibung\&dkz=33212\&_adf.ctrl-state=bmknfearu_1\& afrLoop=1739884697752714]. (Retrieved: 25.07.2016). 
12. Robert Koch Institute. How do GPs and internists vaccinate? Results of a recent survey regarding attitudes and behavior. Epidemiol Bull. 2000;45:357-60.

13. Nichol KL, Zimmermann R. Generalist and Subspecialist Physicians' Knowledge, Attitudes, and Practices Regarding Influenza and Pneumococcal Vaccinations for Elderly and Other High-Risk Patients. Arch Intern Med. 2001; 161:2702-8.

14. Ridda I, Lindley IR, Gao Z, McIntyre P, Macintyre CR. Differences in attitudes, beliefs and knowledge of hospital health care workers and community doctors to vaccination of older people. Vaccine. 2008;26(44):5633-40.

15. Porst R. Pretests for Evaluation of the questionnaire(-draft). In: Sahner $H$, Bayer M, Sackmann R, editors. Questionnaire. A Workbook. 4th ed. Wiesbaden: Springer VS; 2014. p. 189-205

16. Klose J, Rehbein I. Atlas of physicians 2015 - Data on density of panel physicians. In: Atlas of Physicians. Berlin: Scientific Institute of the AOK; 2015.

17. Statutory health insurance physicians (Number). Outline features: years, region, sex, participation status, specialty. [http://www.gbe-bund.de]. (Retrieved: 25.07. 2016).

18. Employee in health service in 1000. Outline features: Year, Germany, Sex, Facility, Occupation. [www.gbe-bund.de]. (Retrieved: 25.07.2016).

19. Destatis. Population and Occupation. Preliminary results of the population updateable on the basis of the Zensus 2011. Wiesbaden: The Federal Statistical Office (Destatis): 2015.

20. Pielak KL, McIntyre CC, Tu AW, Remple VP, Halperin B, Buxton JA. Identifying attitudes, beliefs and reported practices of nurses and doctors as immunization providers. J Adv Nurs. 2010;66(7):1602-11.

21. Attitudes, Knowledge and Practices of the general population regarding hygiene and protection of infections. [http://www.bzga.de/forschung/ studien-untersuchungen/studien/impfen-und-hygiene/]. (Retrieved: 25.07. 2016).

22. National-Association-of-Statutory-Health-Insurance-Physicians, NationalAssociation-of-Statutory-Health-Insurance-Funds. Federal Master Treaty for Medical Practitioners, Enclosure 24. Dtsch Arztebl Int. 2013;110:A1757-60.

23. Güthlin C, Beyer M, Erler A, Gensichen J, Hoffmann B, Mergenthal K, Müller V, Muth C, Petersen JJ, Gerlach FM. Recruitment of Family Practitioners for Research. Experiences from Five Studies. Z Allg Med. 2012;88(4):173-81.

24. Nowalk MP, Zimmerman RK, Feghali J. Missed opportunities for adult immunization in diverse primary care office settings. Vaccine. 2004;22(25-26): 3457-63.

25. Recall-System. [http://www.kvhb.de/recall-system]. (Retrieved: 25.07.2016).

26. Hindringer B. Recall-Systems in physician practices. Diverse fields of application. PRAXiS Dtsch Arztebl. 2007:104(19):16-7.

27. Prinz S, Rashid A. Online management of appointments. Many potentials for physician practices. PRAXiS Dtsch Arztebl. 2015:112(15):8-10.

28. Vaccination Services. [http://www.thepsi.ie/gns/pharmacy-practice/practiceguidance/PharmacyServices/Naccination_Service.aspx]. (Retrieved: 25.07. 2016).

29. Report on the Evaluation of the Seasonal Influenza Vaccination Service in Pharmacy 2014/2015. The Pharmaceutical Society of Ireland; 2015. [http:// www.thepsi.ie/Libraries/Pharmacy_Practice/PSI_2014_15_Report_on_ Seasonal_Influenza_Vaccination_Service.sflb.ashx]. (Retrieved: 25.07.2016).

30. Patient Feedback on the Flu Vaccination Service Provided in Pharmacies. The Pharmaceutical Society of Ireland; 2016. [http://thepsi.ie/Libraries/ Practice_Guidance/Report_on_Patient_Feedback_on_the_Flu_Vaccination_ Service_Provided_in_Pharmacies.sflb.ashx]. (Retrieved 25.07.2016).

31. Voelker R. Physicians' Offices Play Key Role in Promoting Vaccination to Adult Patients. JAMA. 2012;307(6):552.

\section{Submit your next manuscript to BioMed Central and we will help you at every step:}

- We accept pre-submission inquiries

- Our selector tool helps you to find the most relevant journal

- We provide round the clock customer support

- Convenient online submission

- Thorough peer review

- Inclusion in PubMed and all major indexing services

- Maximum visibility for your research

Submit your manuscript at www.biomedcentral.com/submit
Biomed Central 